\section{The effects of intralist cues, extralist cues, and category names on categorized recall*}

\author{
ROBERT L. HUDSON† and JERRY L. DAVIS \\ Mississippi State University, State College, Miss. 39762
}

Two experiments are reported which attempt to clarify a procedural problem of Hudson \& Austin (1970) and provide support for the hypothesis that context words as recall cues serve to mediate category names. The results regarding the procedural problem of Hudson \& Austin (1970) indicate that exposure to context words during recall trials does not artifactually increase recall for context groups. The hypothesis that context cues serve to mediate the category name was supported in Experiment II but not in Experiment I.

Slamecka (1968) presented a series of experiments, the results of which he interpreted as support for an independent storage-retrieval model of word recall. His basic procedure was to cue the experimental Ss (context group) with words from the list and compare their proportionate recall with that of a noncued control group. His results indicated essentially no differences between the two groups, and he interpreted these findings as indicating that each to-be-remembered (TBR) word is stored independently of all other TBR words.

Hudson \& Austin (1970) pointed out that one could predict superior recall for a context group only when (1) the context words were, or mediated, retrieval cues for higher order units, and (2) the presence of the context words, acting as retrieval cues or mediating retrieval cues, resulted in the retrieval of more higher order units than $S$ would recall unaided. They further pointed out that it would seem doubtful that Slamecka's (1968) experiments met one or both of these requirements.

Hudson \& Austin (1970, Experiment I) presented Ss with three words from each of 10 taxonomic categories for five presentation-recall trials. They had a context group which was presented one word from each category at recall, a control group with no cues given at recall, and a category group with the 10 category names given as recall cues at each trial. Their results for number of critical words recalled indicated that the context and category groups were essentially equivalent, while both significantly exceeded the control group.

As was pointed out by Hudson \& Austin (1970), the study contained a

*This research was partially supported by institutional funds granted to Mississippi State University by the National Science Foundation.

tRequests for reprints should be sent to Robert L. Hudson, P.O. Drawer PF Mississippi State University, State College, Miss. 39762 . procedural problem which made the data for the context group somewhat equivocal beyond the first trial. This was, of course, the fact that the context group had been exposed to the TBR words more than had either the category or control groups.

The present study was designed to determine if this additional exposure resulted in more words recalled for the context group on later trials. In addition to the three groups used by Hudson \& Austin (1970), another group of Ss received, as context cues, words from the same categories as the TBR items but which were not used as TBR items in the stimulus list. The reasoning here was that if the context words served as recall cues either directly or by mediation of the category name, extralist cues should serve equally well as intralist cues.

A second purpose of the present investigation was to provide support for the hypothesis that Ss use context which actually serve as the recall cues. This is difficult to demonstrate because one must hypothesize that the context and category groups will do equally well if, in fact, the intralist or extralist cue serves to mediate the category name that is the "real" retrieval cue. In the present study, all of the groups were divided so that half of the Ss in each group learned TBR items that were high associates of the category names while the other Ss learned items that were low associates of the category names. The reasoning here was that for noncued recall, there is ample evidence (e.g., Bousfield, Cohen, \& Whitmarsh, 1958; Deese, 1959) that one would expect the group having the high TBR words to exceed the group having the low TBR words. One might expect that cuing with the category name would either decrease or eliminate this difference. If the Ss use intra- or extracontext cues as mediators for the category names, one would expect that this would decrease or eliminate differences between high and low TBR word words to mediate category names groups, since the structure of the list should be just as obvious whether the words are high or low in taxonomic strength. If the effect is direct, however, one would have to predict that the high TBR groups would exceed the low TBR groups, because one would expect that the direct associations between cue words and high taxonomic TBR words would be much stronger than between cue words and low taxonomic TBR words.

Therefore, the design of Experiment I was as follows: a 4 by 2 by 8 factorial design employing eight presentation-recall trials, four levels of cuing, and two levels of associative strength. The names for the resulting eight groups are: category name cue-high associates (CN-H), category name cue-low associates (CN-L), intralist context cue-high associates (IC-H), intralist context cue-low associates (IC-L), extralist context cue-high associates (EC-H), extralist context cue-low associates (EC-L), no cue control-high associates (NC-H), and no cue control-low associates (NC-L). The overall hypothesis of the study, then, was $\mathrm{CN}-\mathrm{H}=\mathrm{CN}-\mathrm{L}=\mathrm{IC}-\mathrm{H}$ $=\mathrm{IC}-\mathrm{L}=\mathrm{EC}-\mathrm{H}=\mathrm{EC}-\mathrm{L}>\mathrm{NC}-\mathrm{H}>\mathrm{NC}-\mathrm{L}$ for proportion of total words recalled.

\section{EXPERIMENT I}

Subjects

The Ss were 120 male and female undergraduate students enrolled in psychology classes at Mississippi State University. All Ss participated in the experiment to partially fulfill a course requirement.

Ten categories were selected from the extended Connecticut category norms of Battig \& Montague (1969). From each of these 10 categories, 8 words of relatively high frequency (rank order range was from 1st through 12th, with a median rank of 5 ) were chosen. From these 80 words, three approximately equivalent lists of 40 words were prepared, with 4 words per category. This was done by choosing 4 words from each category at random, with the restriction that each word in each category appear in at least one and no more than two lists. An equal number of Ss from each experimental condition were tested, using each of the three lists. This procedure of list construction was followed in order to insure some generality of the results.

A parallel procedure to that just given was followed for words of relatively low frequency, using the same 10 categories. These words had a rank order range of 11 to 41 , with a median rank of 20 .

All words were typed on $2 \times 2$ in. transparent slides for presentation with a Kodak Carousel projector.

Eight different sets of instruction 
Table 1

Mean Percentage of Words Recalled as a Function of Condition for Experiment I

\begin{tabular}{|c|c|c|c|c|c|c|c|c|c|}
\hline \multirow[b]{2}{*}{ Condition } & \multicolumn{8}{|c|}{ Trial } & \multirow[b]{2}{*}{$\Sigma \bar{x}$} \\
\hline & 1 & 2 & 3 & 4 & 5 & 6 & 7 & 8 & \\
\hline CN-H & .40 & .58 & .69 & .73 & .78 & .78 & .80 & .82 & $\mathbf{5 . 5 8}$ \\
\hline CN-L & .34 & .60 & .68 & .77 & .81 & .85 & .88 & .90 & 5.83 \\
\hline $\mathrm{NC}-\mathrm{H}$ & .34 & .51 & .63 & .67 & .71 & .75 & .76 & .83 & 5.20 \\
\hline NC-L & .33 & .51 & .65 & .69 & .76 & .79 & .81 & .83 & 5.37 \\
\hline EC-H & .39 & .53 & .67 & .72 & .82 & .80 & .83 & .87 & 5.63 \\
\hline EC-L & .31 & .45 & .57 & .65 & .71 & .78 & .80 & .83 & 5.10 \\
\hline IC-H & .40 & .54 & .69 & .75 & .80 & .82 & .82 & .89 & 5.71 \\
\hline IC-L & .32 & .45 & .54 & .65 & .68 & .72 & .78 & .82 & 4.96 \\
\hline
\end{tabular}

booklets were prepared, and their differences constituted the different levels of the independent variables of cue and association level used in this study.

The booklets of all Ss stated that the words they were to see could be placed into one of 10 categories, and the categories were stated. The recall sheets of the no-cue groups contained no other information regarding the nature of the list. The category-name groups listed, horizontally, the category names. They were in a different random order on each recall sheet. The recall sheets of the intralist cue groups listed one word from each category, horizontally, and asked for recall of the remaining words. The words listed were varied from sheet to sheet in a random manner, with the restriction that each word appear once in the first four sheets and once in the second four sheets. The order regarding the category from which the words came varied randomly from trial to trial. The recall sheets of the extralist cue groups listed one word per category from the four words not being used for that group as TBR words. Each of the four words was used once in the first four recall sheets and once in the second four recall sheets. The order regarding the category from which the words came was varied randomly from trial to trial. It should be pointed out that those Ss in the context conditions who were given high-associative TBR words also had high-associative cue words, and those Ss who were given low-associative TBR words also had low-associative cue words. Procedure

The Ss were tested, generally, in groups of eight, with two Ss being assigned randomly to each of the four context conditions. The E assigned at random the entire group of eight Ss to either the high-associate condition or the low-associate condition and to one of three equivalent stimulus lists. The Ss were seated approximately $5 \frac{1}{2} \mathrm{ft}$ from a daylight-type screen, and the projected image was approximately $4 \frac{1}{2}$ in, in height. A total of 15 Ss were tested under each of the eight (4 context by 2 association) conditions.
An equal number of $S s$ from each condition were tested under each of the three equivalent high-strength stimulus lists and the three equivalent low-strength stimulus lists. The words were presented at a 2 -sec rate. After each presentation, the $S$ s were given $2 \mathrm{~min}$ for recall before the start of the next presentation trial. Eight presentation-recall trials were completed, with words being presented in a different quasirandom order on each presentation. Results

The data were initially examined in terms of number of words recalled on each trial by Ss in each condition. The raw data were changed to percentages to allow a comparison of the three pairs of conditions, i.e., $\mathrm{CN}, \mathrm{NC}$, and $\mathrm{EC}$, in which Ss were asked to recall 40 TBR items with the pair of IC conditions in which Ss were asked to recall only 30 TBR items. Table 1 presents the mean percentage of words recalled by each of the eight groups on each of the eight recall trials.

A 4 by 2 by 8 split-plot factorial analysis of variance was employed to analyze the data. The analysis indicated a significant cuing condition effect, $F(3,112)=3.07, p<.05$, a significant Cuing Condition by Level of Association interaction effect, $\mathrm{F}(3,112)=4.79, \mathrm{p}<.01$, and $\mathrm{a}$ significant trials effect, $F(7,784)=$ $218.65, p<.001$. The other analyses were short of significance.

Simple main effects of the Cuing Condition by Level of Association interaction were computed, and subsequent multiple comparisons were made using Tukey's HSD test.
Significant differences were noted $(\mathrm{p}<.05)$ for cuing conditions at the low level of association, with the $\mathrm{Ss}$ in the NC-L, EC-L, and IC-L conditions not differing significantly but recalling significantly $(\mathrm{p}<.05)$ fewer words than did the CN-L Ss. In addition, the EC-H group significantly $(\mathrm{p}<.05)$ exceeded the EC-L group, and the IC-H group significantly $(p<.05)$ exceeded the IC-L group. The $\mathrm{CN}-\mathrm{H}$ group did not differ significantly from the CN-L group, nor did the NC-H group significantly exceed the NC-L group.

Table 2 presents the mean number of categories recalled by $\mathrm{Ss}$ in each of the eight conditions. A category was said to be represented on a given trial when at least one TBR item from that category was recalled (Cohen, 1966).

A 4 by 2 by 8 split-plot factorial analysis of variance was performed, resulting in the discovery of a significant cuing condition main effect, $F(3,112)=7.28, p<.05, a$ significant trials main effect, $F(7,784)$ $=79.84, \mathrm{p}<.01$, and a significant Cuing Condition by Trials interaction, $F(21,784)=1.93, p<.05$. Furthermore, the analysis demonstrated that the Ss in the four high-level-of-association groups recalled significantly more categories, $F(1,112)=4.09, \mathrm{p}<.05$, than did Ss receiving items low in associational value to the category names. The Cuing Condition by Level of Association interaction was just short of significance, with $F(3,112)=2.46$, $p>.05$. The other $F$ ratios were not significant.

Simple main effects were computed for the Cuing Condition by Trials interaction, and the results indicated significant differences $(p<.05)$ between the cuing conditions on Recall Trials 1, 2, and 3, with differences on subsequent trials being nonsignificant $(p>.05)$. A Tukey's test was used to compare the means of the cuing conditions at Trials 1,2 , and 3 . It was found that on Trials 1 and 2 , the $\mathrm{CN}$ Ss recalled significantly more categories $(p<.05)$ than did the NC, EC, or IC Ss, among which there were no significant differences. On Trial 3 ,

Table 2

Mean Number of Categories Recalled as a Function of Condition for Experiment 1 . Trial

\begin{tabular}{ccccccccccc}
\cline { 2 - 6 } Condition & $\mathbf{1}$ & $\mathbf{2}$ & $\mathbf{3}$ & $\mathbf{4}$ & $\mathbf{5}$ & $\mathbf{6}$ & $\mathbf{7}$ & $\mathbf{8}$ & $\Sigma \overline{\mathrm{X}}$ \\
\hline CN-H & $\mathbf{8 . 5 3}$ & $\mathbf{9 . 8 7}$ & $\mathbf{9 . 7 3}$ & $\mathbf{9 . 6 7}$ & $\mathbf{9 . 9 3}$ & $\mathbf{9 . 6 7}$ & $\mathbf{9 . 8 7}$ & $\mathbf{9 . 9 3}$ & $\mathbf{7 7 . 2 0}$ \\
CN-L & $\mathbf{8 . 5 3}$ & $\mathbf{9 . 6 0}$ & $\mathbf{9 . 6 0}$ & $\mathbf{9 . 6 0}$ & $\mathbf{9 . 8 0}$ & $\mathbf{9 . 6 0}$ & $\mathbf{1 0 . 0 0}$ & $\mathbf{9 . 8 7}$ & $\mathbf{7 6 . 6 0}$ \\
NC-H & $\mathbf{7 . 4 0}$ & $\mathbf{8 . 5 3}$ & $\mathbf{9 . 2 0}$ & $\mathbf{9 . 2 0}$ & $\mathbf{9 . 2 0}$ & $\mathbf{9 . 4 0}$ & $\mathbf{9 . 4 7}$ & $\mathbf{9 . 6 7}$ & $\mathbf{7 2 . 0 7}$ \\
NC-L & $\mathbf{7 . 6 0}$ & $\mathbf{9 . 0 0}$ & $\mathbf{9 . 6 7}$ & $\mathbf{9 . 2 0}$ & $\mathbf{9 . 4 7}$ & $\mathbf{9 . 4 0}$ & $\mathbf{9 . 4 7}$ & $\mathbf{9 . 6 7}$ & $\mathbf{7 3 . 4 8}$ \\
EC-H & $\mathbf{8 . 2 0}$ & $\mathbf{9 . 2 7}$ & $\mathbf{9 . 9 3}$ & $\mathbf{9 . 9 3}$ & $\mathbf{9 . 8 7}$ & $\mathbf{9 . 6 7}$ & $\mathbf{1 0 . 0 0}$ & $\mathbf{1 0 . 0 0}$ & $\mathbf{7 6 . 8 7}$ \\
EC-L & $\mathbf{7 . 6 0}$ & $\mathbf{8 . 6 7}$ & $\mathbf{9 . 1 3}$ & $\mathbf{9 . 5 3}$ & $\mathbf{9 . 4 0}$ & $\mathbf{9 . 6 7}$ & $\mathbf{9 . 8 0}$ & $\mathbf{9 . 7 3}$ & $\mathbf{7 3 . 5 3}$ \\
IC-H & $\mathbf{8 . 0 7}$ & $\mathbf{8 . 7 3}$ & $\mathbf{9 . 0 7}$ & $\mathbf{9 . 5 3}$ & $\mathbf{9 . 6 7}$ & $\mathbf{9 . 8 0}$ & $\mathbf{9 . 6 7}$ & $\mathbf{9 . 9 3}$ & $\mathbf{7 4 . 4 7}$ \\
IC-L & $\mathbf{6 . 6 0}$ & $\mathbf{8 . 5 3}$ & $\mathbf{8 . 9 3}$ & $\mathbf{9 . 2 0}$ & $\mathbf{9 . 2 7}$ & $\mathbf{9 . 2 7}$ & $\mathbf{9 . 4 7}$ & $\mathbf{9 . 6 0}$ & $\mathbf{7 0 . 8 7}$
\end{tabular}


the CN Ss significantly exceeded $(p<.05)$ only the IC Ss, with no significant differences being noted between the other groups.

Even though the Cuing Condition by Level of Association interaction was short of the .05 level of significance, simple main effects were computed and followed where appropriate by Tukey's HSD test. The results indicated that the $\mathrm{CN}-\mathrm{H}$ and EC-H groups both significantly exceeded the NC-H group; the CN-L group significantly exceeded the IC-L group; the EC-H group exceeded the EC-L group; and the IC-H group exceeded the IC-L group.

Table 3 presents the mean proportion of words recalled per category recalled to total possible recall per category (PROP) for each of the eight groups for each trial. These data were collapsed over trials, and a completely randomized 2 by 4 analysis of variance was performed. The only significant $F$ was that of the Cuing Conditions by Level of Association interaction, with $\mathrm{F}(3,112)=11.59$, $\mathrm{p}<.01$. Subsequent analysis of simple main effects and, where appropriate, Tukey's test indicated that CN-L significantly exceeded both EC-L and IC-L. Further, IC-H significantly exceeded IC-L. No other comparisons were significant.

A major purpose of the present experiment was to assess the effects of a possible confounding found in an experiment by Hudson \& Austin (1970) resulting from additional exposure to the TBR items for groups cued at recall with items from the list. This was essentially accomplished by adding an extralist context condition in which additional exposure to TBR items was eliminated by presentation of context words from the stimulus list categories that were not included among the TBR items.

The data of primary interest to this question are the percentages of words recalled by the $S s$ in the four high-level-of-association groups. Although the comparisons between groups were not significant, there is a definite trend present that essentially replicates the results of Hudson and Austin, i.e., there were essentially no differences among the CN-H, EC-H, and IC-H groups, while all three exceeded the performance of the NC-H group. Based on the data of Hudson \& Austin (1970), it would seem that all of the cued groups failed to recall as many words as might have been expected on the early trials. Comparisons were made between the IC and EC conditions in regard to the number of words recalled, number of categories recalled, and tendency to exhaust recalled categories (PROP). In

Table 3

Mean Percentage of Words Recalled Per Category Recalled to Total Possible as a Function of Condition for Experiment II

\begin{tabular}{|c|c|c|c|c|c|c|c|c|c|}
\hline \multirow[b]{2}{*}{ Condition } & \multicolumn{8}{|c|}{ Trial } & \multirow[b]{2}{*}{$\sum \overline{\mathrm{X}}$} \\
\hline & 1 & 2 & 3 & 4 & 5 & 6 & 7 & 8 & \\
\hline $\mathrm{CN}-\mathrm{H}$ & .46 & .59 & .70 & .75 & .80 & .80 & .81 & .83 & 5.74 \\
\hline CN-L & .40 & .62 & .71 & .81 & .83 & .89 & .88 & .92 & 6.06 \\
\hline $\mathrm{NC}-\mathrm{H}$ & .47 & .60 & .67 & .75 & .77 & .80 & .79 & .86 & 5.71 \\
\hline NC-L & .41 & .57 & .67 & .75 & .81 & .84 & .86 & .86 & 5.77 \\
\hline EC-H & .48 & .57 & .67 & .72 & .83 & .82 & .83 & .87 & 5.79 \\
\hline EC-L & .40 & .51 & .63 & .68 & .76 & .80 & .81 & .85 & 5.44 \\
\hline IC-H & .49 & .61 & .75 & .78 & .82 & .82 & .85 & .90 & 6.02 \\
\hline IC-L & .48 & .53 & .61 & .70 & .73 & .76 & .82 & .86 & 5.49 \\
\hline
\end{tabular}

every case, the IC and EC Ss performed at comparable levels, with no significant differences in either the high- or low-level-of-association data. Further, as in previous studies, the depression of the NC-H group was the result of recall of fewer categories. Thus, it would seem that the data of Hudson and Austin can reasonably be interpreted at face value beyond Trial 1.

A second purpose of this study was to provide support for the hypothesis of Hudson and Austin regarding the manner in which context cues affect recall. They speculated that the context word served to mediate the category name that served as the actual recall cue.

The data, however, do not support the hypothesis in that the EC-L and IC-L groups are definitely not equivalent to the EC-H and IC-H groups in percent words recalled, even though the CN-L group is equivalent to the $\mathrm{CN} \cdot \mathrm{H}$ group. This difference in percent words recalled is a product of both a decrease in number of categories and recall per category. Thus, it may be that when the words are high in associative strength, context cues are used to mediate the category name, whereas when the words are low in associative strength, the context cues are used in some more direct manner.

One could just as easily speculate, however, that the EC-H, EC-L, IC-H, and IC-L groups all use the context cues to generate free associates, but, whereas many free associates to a high cue will likely be contained in the TBR words that ranked high, it is considerably less likely that the free associates to a low cue will be contained in the low TBR words.

It should be pointed out here that for the IC-L, IC-H, EC-L, and EC-H groups, there is an implicit confounding in this study. This arises from the fact that, since TBR words for the high groups differ from those of the low groups, the intralist context cues also differed. Therefore, the IC-L and IC-H groups not only differed on the association value of the TBR words, but also on the association value of the cue words. Although it was not implicitly necessary, the EC-H and EC-L groups also had cues corresponding in association value to the TBR words.

Part of this problem of the manner in which cue words are utilized could probably be sorted out by conducting a study where high and low TBR words were orthogonally combined with high and low extralist cues. The fact that the high-association groups recalled significantly more categories than did the low-association groups might have resulted from cue differences or from TBR word differences. Inspection of Table 2 indicates that the major part of this difference is due to the difference between the EC-H and EC-L groups and the IC-H and IC-L groups. This would indicate that the difference was primarily a result of cue differences.

EXPERIMENT II

Experiment II was performed in an attempt to further analyze the role the context word plays in the storage-retrieval process. The results of Experiment I did not support the hypothesis that the context word serves to mediate the category name. In the present study, four groups were formed in a manner similar to the Hudson \& Austin (1970) study. The category group was given the list of categories on each recall trial. The Context 1 (Con-1) group was given one word from each category as context. The Context 2 ((Con-2) group was given two words from each category as context. The control group was given no cue during recall trials. All Ss were told prior to word presentation that the words could be categorized and were told the category names. To further extend the Hudson \& Austin (1970) findings, 45 words, 3 from each of 15 taxonomic categories, were used.

The reasoning was that, if the effect of the context word was to mediate the category name, then the proportion of critical words recalled by the Con- 1 and Con- 2 groups should not differ. On the other hand, if the effect of the context is a direct one, then the more words in the context, 


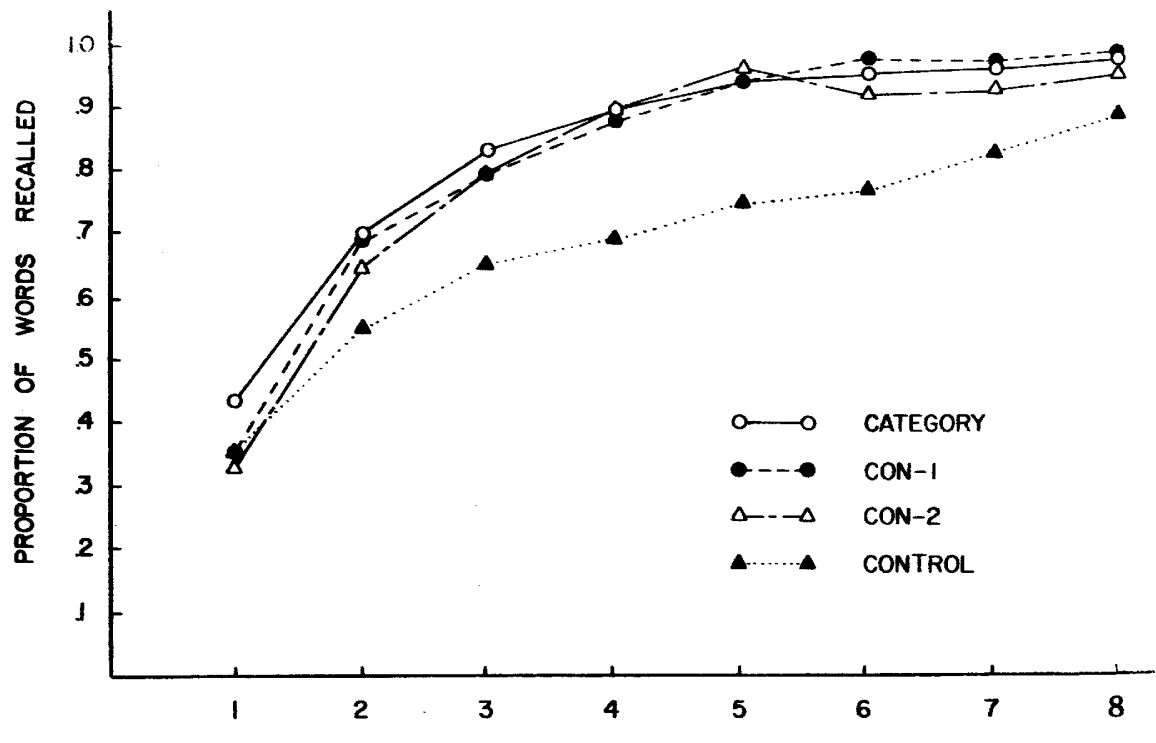

TRIAL

Fig. 1. Mean proportion of words recalled for the four conditions for each of the eight trials for Experiment II.

the higher the probability that the remaining words will be recalled. Therefore, we hypothesized that the proportion of critical words recalled would not differ for the category, Con-1, and Con-2 groups, but that all three would be superior to the control group.

\section{Subjects}

The Ss were 28 introductory psychology students, who served in order to satisfy a course requirement. All were naive with respect to verbal learning research. There were 7 Ss under each of the four conditions.

\section{Materials}

Three words were chosen from each of 15 categories of the extended Connecticut category norms of Battig \& Montague (1969). The words were of a relatively high association value. Procedure

The Ss were tested individually, with random assignment to the four conditions in blocks of four. The basic group was the control group, which was given "standard" repeated free recall instructions complete with the information that the words could be and were returned after the recall period. The context sheets were shuffled so that each $S$ had a different sequence over the eight trials.

Four random orderings of the 45 words were prepared for use with a Stowe memory drum. Each S was assigned a random starting order, went through the four lists in forward order, started at another random order for Trial 5, and went through the four lists in reverse order for a total of eight presentation-recall trials. The words were presented at a 2.5 sec rate, with $2.5 \mathrm{~min}$ allowed for each recall period. Results

The mean proportion of words recalled for the four groups at each trial is presented in Fig. 1. A 4 by 8 split-plot analysis of variance was carried out on these data, with the following results: conditions, $F(3,23)$ $=3.68, p<.05$; trials, $F(7,168)=$ 146.27, p<.01; interaction, $F(21,168)=1.27, p>.05$. Individual paired comparisons of the category, Con-1, and Con-2 groups with the control group, using Tukey's HSD procedure, indicated that all three groups exceeded the control group (ps $<.05$ ). The category, Con-1, and Con-2 groups obviously did not differ among themselves.

Table 4 presents the mean number of categories recalled (CR), where recall of a category is defined to be recall of at least one word from the category (Cohen, 1966). Direct comparisons of the groups on mean number of words recalled per category recalled are difficult, since the possible number of words which could be recalled per category varies. Therefore, Table 3 included the mean proportion of words recalled per category recalled to possible total recall per category (PROP). These data are not presented for the Con-2 group as they are either meaningless or redundant with Fig. 1.

The number of categories recalled were analyzed with a split-plot analysis of variance for the category, Con-1, and control groups through the first five trials. The analysis indicated a significant cuing effect, with $F(2,86)=$ $4.85, \mathrm{p}<.05$, and a significant trials effect, with $F(4,74)=43.29, p<.01$. The Cuing Conditions by Trials

Table 4

Mean Number of Categories Reealled (CR) and Mean Percentage of Woris Recalled Per Catezory Reealled to Total Posible (PROR) as a Function of Condition for Experiment II

\begin{tabular}{|c|c|c|c|c|c|c|c|c|c|}
\hline \multirow[b]{2}{*}{ Measure } & \multirow[b]{2}{*}{ Condition } & \multicolumn{8}{|c|}{ Trial } \\
\hline & & 1 & 2 & 3 & 4 & 5 & 6 & 7 & 8 \\
\hline $\mathbf{C R}$ & $\begin{array}{l}\text { Category } \\
\text { Con-1 } \\
\text { Control }\end{array}$ & $\begin{array}{r}11.7 \\
8.9 \\
9.3\end{array}$ & $\begin{array}{l}14.4 \\
12.9 \\
12.1\end{array}$ & $\begin{array}{l}14.6 \\
13.4 \\
13.3\end{array}$ & $\begin{array}{l}14.6 \\
14.4 \\
12.9\end{array}$ & $\begin{array}{l}14.9 \\
15.0 \\
13.3\end{array}$ & $\begin{array}{l}15.0 \\
15.0 \\
13.1\end{array}$ & $\begin{array}{l}15.0 \\
14.9 \\
13.7\end{array}$ & $\begin{array}{l}15.0 \\
15.0 \\
13.7\end{array}$ \\
\hline PROP & $\begin{array}{l}\text { Category } \\
\text { Con-1 } \\
\text { Control }\end{array}$ & $\begin{array}{l}.56 \\
.62 \\
.58\end{array}$ & $\begin{array}{l}.72 \\
.81 \\
.69\end{array}$ & $\begin{array}{l}.86 \\
.89 \\
.74\end{array}$ & $\begin{array}{l}.93 \\
.92 \\
.81\end{array}$ & $\begin{array}{l}.93 \\
.95 \\
.84\end{array}$ & $\begin{array}{l}.96 \\
.98 \\
.88\end{array}$ & $\begin{array}{l}.97 \\
.99 \\
.91\end{array}$ & $\begin{array}{l}.98 \\
.99 \\
.97\end{array}$ \\
\hline
\end{tabular}


interaction was short of significance at the .05 level, with $F(8,74)=1.91$, $\mathrm{p}<.10$. Nevertheless, it is obvious that the category group is superior to the Con-1 and control groups on Trial 1 and that the Con-1 group catches up with the category group on Trial 4, while both continue to be superior to the control group.

The number of words recalled per category, expressed as a proportion of possible recall per category (PROP), were also analyzed with a split-plot analysis of variance over the first five trials. The results indicated only the Cuing Condition by Trials interaction to be significant, with $F(8,74)=2.32$, $\mathrm{p}<.05$. As can be seen from inspection of Table 4, this significant interaction resulted from a more sapid increase across trials for the Con-1 and category groups than for the control group.

Discussion

It would appear that the hypothesis was supported. There was essentially no difference between the Con-1 and Con-2 groups and both were almost identical with the category group on percent words recalled. Another way of stating these results is to say that the probability of a given word's being recalled is the same regardless of whether one context word, two context words, or the category name was given. The probability was considerably less if no cue was given. This was true even though the Con-2 group was actually exposed to the words more than was the context group. Therefore, from all apearances, the context groups used the context to mediate the category name rather than as a direct associative device. It should be noted, however, that the words of Experiment II were of a relatively high association level. The same results should not necessarily be expected for words of a low association level.

It should also be pointed out that even though the category and Con-1 groups do not differ on percent of words recalled, they do differ on early trials on both number of categories and PROP. In fact, the Con-1 group compensates for a lowered number of categories recalled by having a higher PROP than the category group. Thus, there is some doubt that a cue word is, in fact, functionally equivalent to a category name. However, it may be that these differences in categories recalled and PROP are artifacts of basing the percentages on different possible words. Inspection of Table 1 indicates a similar tradeoff relationship between categories recalled and PROP for the $\mathrm{CN} \cdot \mathrm{H}$ and IC-H groups. This trend, however, is essentially nonexistent in a comparison of the $\mathrm{CN}-\mathrm{H}$ and EC-H groups.

\section{REFERENCES}

BATTIG, W. F., \& MONTAGUE, W. E. Category norms for verbal items in 56 categories: A replication and extension of the Connecticut category norms. Journal of Experimental Psychology, 1969,80, (3, Pt. 2).

BOUSFIELD, w. A., COHEN, B. H., \& WHITMARSH, G. A. A ssociative clustering in the recall of words of different taxonomic frequencies of occurrence. Psychological Reports, 1958. 4, 39-44.

COHEN, B. H. Some-or-none characteristics of coding. Journal of Verbal Learning \& Verbal Behavior, 1966, 5, 182-187.

DEESE, J. Influence of inter-item associative strength upon immediate free recall. Psychological Reports, 1959, 5, 305-312.

HUDSON, R. L., \& AUSTIN, J, B. Effect of context and category name on the recall of categorized word lists. Journal of Experimental Psychology, 1970, 86, 43-47.

SLAMECKA, N. J. An examination of trace storage in free recall. Journal of Experimental Psychology, 1968, 76 , 504-513. 